\title{
Long-term mental health in unaccompanied refugee minors: Pre- and post-flight predictors
}

Tine K. Jensen, licensed psychologist, PhD, Professor, Department of Psychology, University of Oslo, Norway. Forskningsveien 3A, 0373 Oslo, Norway, and the Norwegian Centre for Violence and Traumatic Stress Studies, Gullhaugveien 1-3, Nydalen, Oslo, Norway. Email: tine.jensen@psykologi.uio.no. Phone: +47 41327827. ORCID: 0000-002-0751-0228

Ane-Marthe Solheim Skar, MA, PhD, University of Oslo, Norway. Forskningsveien 3A, 0373 Oslo, Norway, and the Norwegian Centre for Violence and Traumatic Stress Studies, Gullhaugveien 1-3, Nydalen, Oslo, Norway.

Elin Sofia Andersson, licensed psychologist, PhD candidate, Norwegian Centre for Violence and Traumatic Stress Studies. Gullhaugveien 1-3, Nydalen, Oslo, Norway.

Marianne Skogbrott Birkeland, licensed psychologist, $\mathrm{PhD}$, Norwegian Centre for Violence and Traumatic Stress Studies. Gullhaugveien 1-3, Nydalen, Oslo, Norway. ORCID: 00000002-2388-8474

\section{Acknowledgments}

We would like to thank all the young refugees for participating in this study, and Tore Wentzel-Larsen for his statistical advice and comments. This work was supported by grants from The Norwegian Directorate of Health, and the Norwegian Extra Foundation for Health and Rehabilitation through The Norwegian Council for Mental Health. 


\begin{abstract}
Unaccompanied refugee minors are a particularly vulnerable group. The aim of this study is to increase our knowledge about possible pathways to wellbeing and integration for unaccompanied refugee minors as they strive to establish new lives in a host county. The present study followed a group of youth who fled to Norway without their caregivers at three time points; 6 months ( $n=95 ; M$ age $=13.8,80 \%$ boys), 2 years $(n=78 ; M$ age $=16.5,83 \%$ boys), and 5 years ( $n=47$; M age 20.0, 83\% boys) after arrival. Linear mixed effects models were used to assess whether age, gender, and trauma exposure prior to arrival were associated with levels and changes in symptoms of posttraumatic stress (PTS), depression, anxiety, and externalizing symptoms over time. Regression analyses were conducted to examine whether daily hassles, perceived social support, and new trauma experiences predict PTS, internalization, externalization, and somatization. The mean levels of depression had decreased significantly at five years but mean levels of anxiety, PTS and externalizing symptoms did not. Females and severely trauma-exposed had higher levels of symptoms. Higher age was associated with less change in symptoms of depression and posttraumatic stress over time. Five years after arrival, many still experienced clinical levels of mental health problems, and level of daily hassles was an important predictor. Support may be needed not only at arrival to handle mental health problems in general and post-traumatic stress in particular, but also after resettlement. Help to manage daily hassles may be especially important to ensure wellbeing and integration.
\end{abstract}

Key words: Asylum seekers; daily hassles, social support, mental health trajectories, trauma, somatic complaints 
According to the United Nations Health Commissioner for Refugees, over 68 million people were in 2017 displaced by conflict or persecution. Many of these are children and adolescents who, for different reasons, are not accompanied by their caregivers [1]. These youth are often considered to be the most vulnerable group of refugees [2,3]. The strains associated with preflight experiences, experiences during their flight, and challenges when arriving to their hosting country add up and may contribute to their mental health status and development [4]. In fact, some studies have shown that unaccompanied refugee minors are overrepresented in psychiatric inpatient care [5]. The majority of these youth have experienced severe traumas such as interpersonal violence and abuse, and many have clinically elevated symptoms of post-traumatic stress (PTS), depression, anxiety and externalizing problems [6-10], that persist [11-13]. Although unaccompanied refugee minors are thought to be greatly at risk for developing mental health problems [3,14-17], very few studies have followed these youth over time from arrival at a host country until resettlement in the municipalities $[18,13]$.

Longitudinal studies of refugees are challenging to conduct partly because they often are hard to reach. They move frequently, change their names and many change their phone numbers. As time goes by many are also sent out of the host country because of lack of official papers and documentation. Some choose also to hide in fear of being sent back to their country of origin. Because of this we know very little about predictors of long-term mental health problems. Particularly longitudinal studies that focus on those arriving in their host country when they are 16 years of age or younger are scarce. These children are not only subject to increased risk of mental health problems because of separation from caregivers in their home countries, but also because of high risk for trauma exposure during their flight because they lack protection [2]. Many also experience stress and loneliness after arrival [15]. Since they do not have trusting adults that can help them adjust, it is not surprising that rates of mental health problems after resettlement are high, with posttraumatic stress disorder (PTSD), depression and anxiety being most common [14,6,7]. One can expect younger children to be more at risk since they are more dependent on adults for protection and help in regulating stress. Studies have shown that there is an association between the exposure to pre-migration trauma and PTSD in refugee youth [17]. Also several studies show that girls are more at risk for developing PTSD than boys [19]. Although a clear understanding of why this may be is lacking, it may reflect that girls more often are exposed to interpersonal trauma. High levels of somatic complaints have also been reported and the existing literature suggests that there is a significant and positive relation between traumatization and somatization in adult refugee 
populations [20,21]. However, studies examining somatic complaints are scarce [22], and to our knowledge, only one study has examined somatic symptoms in refugee minors [23]. In this study, seeking medical care for somatic symptoms was associated with behavioral or emotional disorders for most of the youth.

However it is important to keep in mind that not all unaccompanied refugee minors develop mental health or somatic problems, and high rates of resilience are also reported $[24,15,25,26]$. Several studies have shown that social support is a protective factor and that lack of social support sets traumatized youth at risk [27-29]. Strong social support in the host country has been shown to be important for young unaccompanied refugee minors' mental health as well [17,30]. Oppedal \& Idsøe [24] found for instance that social support was associated with symptoms of depression but not PTSD, while others have found an effect for both [31]. In a study from Germany, the importance of perceived social support from family, peers, and adult mentors was examined in 105 male unaccompanied refugee minors from Syria and Afghanistan [30]. Their findings show that high levels of social support from a mentor moderated the association between the number of serious life events the youth had experienced and symptoms of PTSD, depression, and anxiety. They also found a moderating effect of peer support on the relationship between the number of serious life events and anxiety symptoms. Family support had no moderating effects. The study shows that different types of social support may be helpful in different ways and support needs to be adapted to the youths' particular needs. These studies are in line with numerous others showing that social support is important for recovering after trauma [19]. It is important to keep in mind that for youth and young people, migration-related stress intersect with other changes that also non-migrant youth face, such as the transition to adulthood. When transitioning to adulthood, social support and the ability to form new attachments may be formative and influence mental health trajectories, particularly for young persons who have no or very little family ties in their country of residence.

When youth arrive safely in a country, they may experience relief and hope during their initial time in their host country (also referred to as honeymoon effect) [32]. Nonetheless, as time goes by, these feelings may be overshadowed by stress and daily hassles in their everyday life. Unaccompanied refugee minors must cope with the traumatic memories of past experiences while dealing with a new and uncertain life situation in a foreign country without the emotional support from their caregivers. While the role of daily hassles such as discrimination, stress related to legal procedures, living circumstances, lack of money, difficulty making friends etc. have been documented for accompanied refugee minors 
$[18,33,34]$, much less is known about unaccompanied refugee minors. To our knowledge, only a few studies have examined the impact of daily hassles for unaccompanied refugee minors, although none of these include the youngest age groups. Seglem et al. [35] compared daily hassles experienced by resettled unaccompanied refugee minors and ethnic minority youth and majority youth in Norway. Unaccompanied refugees reported higher levels of daily hassles than the other two groups. Daily hassles predicted lower life satisfaction and more depressive symptoms across groups. A negative relationship between daily hassles and depression has also been found to predict negative health trajectories [36]. Vervliet et al. [13] also found that the number of daily stressors had a significant impact on mental health problems. In this study, the youth were followed 6 and 18 months after arriving in Belgium, and the mean number of reported daily stressors increased over time. Importantly though, a large minority of the unaccompanied refugee minors reported few or no daily stressors. The authors conclude that longer follow-up periods are needed to entangle the relationship between earlier and ongoing stress and how this relates to mental health trajectories in unaccompanied refugee minors.

In sum, more longitudinal studies are needed to understand the relationship between trauma exposure, post migration stressors, social support, and mental health [37].

Understanding how trajectories of mental health problems unfold over time and what contributes to positive health may help us to target interventions and build support systems that ease the process towards integration and increase unaccompanied refugee minors' chances to succeed in their resettlement country.

In this paper, we investigate unaccompanied refugee minors mental health trajectories over three time points. First approximately 6 months after arrival to Norway, second about two years later when the youths were resettled in the municipalities, and lastly when the youths had been living in Norway for approximately five years. The study is guided by a conceptual model for predicting mental health problems assuming that the factors influencing mental health are multiple and consist of risks and protective factors. The model includes premigrant factors such as age, gender, and trauma exposure, along with possible maintaining post-migrant factors such as daily hassles and new trauma exposures. Social support is thought to be a protective factor.

This study builds on previous studies reporting on mental health problems in this group at six months (Masked for review) and two years (Masked for review) after arrival, by examining changes in mental health problems, as well as predictors of levels of current mental 
health problems at five years. More specifically, we will examine the following research questions:

1) To what extent have levels of mental health problems in unaccompanied refugee minors changed over the five years since their arrival in Norway?

2) To what extent does age, gender, and trauma exposure prior to arrival relate to changes in mental health problems over this time period?

3) To what extent do the youth report mental health problems after five years in Norway, in terms of levels of posttraumatic stress symptoms, general psychological distress (anxiety, depression, externalizing symptoms), and somatic complaints?

4) To what extent do daily hassles, trauma exposure after arrival to Norway, and perceived social support relate to unaccompanied refugee minors' levels of mental health problems after five years in Norway?

\section{Method}

\section{Procedure and participants}

In this study we follow a group of youth who fled to Norway without a caregiver. The mean age of the children was 13.8 years. In Norway, unaccompanied refugees under 16 years of age are put in the care of the State Child Protection Services. The children are placed in small care centers while waiting to be settled or returned. Upon granted asylum, they are moved into the municipalities and often placed together with 4-6 other refugee youth in apartment units. Here they are attended to by social workers.

The youth were originally recruited from five of six care centers that could accommodate a total of 118 youth. The participants were representative regarding gender distribution and country of origin.

The first wave of data (T1) was collected approximately 6 months after arrival (M=6 months, $\mathrm{SD}=5$ months, range 1-24 months), the second wave (T2) about two years after arrival ( $\mathrm{M}=1.9$ years, $\mathrm{SD}=6$ months, range 0.9 to 2.8 years), and the third wave (T3) about five years after arrival. The T3 assessments were conducted from May 2016 to February 2017.

The total sample consisted of 98 unaccompanied refugee minors ( $81 \%$ boys, $n=79)$. All participants at T1 and T2 were asked if they could be contacted for further follow-up interviews. Those youth who agreed were contacted by telephone. At T1, 95 youth responded to the relevant variables ( $80 \%$ boys, $n=76), 78$ responded at T2 $(83 \%$ boys, $n=65)$, and 47 at $\mathrm{T} 3$ ( $83 \%$ boys, $\mathrm{n}=39$ ). Their mean self-reported age was $13.8, \mathrm{SD}=1.4$ at $\mathrm{T} 1 ; 16.5$ years, 
$\mathrm{SD}=1.6$ at $\mathrm{T} 2$, and 20.0 years, $\mathrm{SD}=1.6$ at T3. A majority was from Afghanistan $(n=22)$. From $\mathrm{T} 1$ to $\mathrm{T} 2$ there were in total 20 drop outs. Of these, 11 did not wish to participate, and the remaining nine had either left the country or had disappeared. After five years, another 31 youth did not participate. Of these, 17 did not wish to participate, 10 were not found, and 4 agreed to participate but we were not able to reach an agreement for time of interview. What we know of, at least 11 of the 21 who we did reach at T3 were either in school and/or had a job, one was in prison and one had his own family with partner and a child.

We do not have information on how much or what kind of psychosocial help the participants have received, but 19 of the 45 youth who at T3 gave consent for us to collect this information have had some contact with child and adolescent mental health services according to data from the Norwegian Patient Registry.

All of the interviews were conducted face to face at a location chosen by the youth, either in their homes, in public meeting rooms, or at the research center. For a more detailed description of the sample and recruitment process, see [papers masked for review].

\section{Measures}

Symptoms of anxiety, depression, and externalizing were measured with the Hopkins Symptom Checklist-37 (HSCL-37A) [38] at T1, T2, and T3. HSCL-37A is a modified version of HSCL-25 specifically developed for unaccompanied asylum-seeking children [39]. This self-report measure includes subscales measuring symptoms of anxiety (10 items, e.g. Feeling tense or keyed up), depression (15 items, e.g. Crying easily), and externalizing (12 items; e.g., Arguing often). The items are rated on a 4-point scale that ranges from 1 (not at all) to 4 (very much) with a sum score from 37 to 148. At T1 and T2, four items related to alcohol, drugs, and loss of sexual interest were considered inappropriate due to the participants' young age, and were omitted and scored as 1 (never). At T3 however, these were administered. The suggested clinical cut-off values are as follows: total score $\geq 69.0$, anxiety $\geq 20.0$, and depression $\geq 33.2$. No cut-off score has been suggested for the externalizing scale [40]. In the current study, the Cronbach's alphas for the total scale were $.90, .94$, and .96 at T1, T2, and T3, respectively. For the anxiety subscale the corresponding numbers were .77, .90, and .94, and for the depression subscale $.86, .91$, and .95 . For the externalizing subscale the numbers were $.62, .64$, and .65 .

Posttraumatic stress symptoms were measured by The Child PTSD Symptom Scale (CPSS) [41] at T1, T2, and T3. The CPSS is a 17-item self-report questionnaire developed for 
children and adolescents between 10 and 18 years. The CPSS measures PTSD symptoms according to the DSM-IV; comprising re-experiencing (5 items, e.g., having bad dreams or nightmares), avoidance (7 items, e.g., Tried not to think, talk or feel about the event(s)) and hyperarousal (5 items, e.g., Trouble falling asleep or sleeping through the night). Symptom frequency for the previous two weeks are rated using a 4-point scale from 0 (Not at all) to 3 (5 or more times a week/almost always). Total sum score ranges from 0 to 51 . The CPSS has demonstrated convergent validity, internal consistency, and test-retest reliability [41]. In the current study, Cronbach's alphas for the 17 items at T1, T2, and T3 were .86, .91, and .93, respectively. The recommended cut-off score indicating clinical elevated symptoms is a total score of 11 or higher [41].

Somatization was measured by Children's Somatization Inventory Short form, CSSI-8 [42] at T3. CSSI-8 includes eight questions on somatization, including pain in stomach, head, lower back, and arms/legs, faintness/dizziness, rapid heartbeat, nausea/stomach problems, and weakness. It is revised from CSSI-24 for use in a study on the 2011 Utøya attack [43], in cooperation with the developer. The items are scored on a five-point scale from 0 (not at all) to 4 ( $a$ whole lot). A summed score was calculated by summing the responses to all the items. A higher sum score indicates more somatization. In the current study, the Cronbach's alpha was .91.

Exposure to trauma prior to arrival to Norway was measured by the Stressful Life Events (SLE) [44] at T1 and T2. This checklist includes 12 dichotomous (yes/no) questions about the experience of severe life events such as separation from family, violence, and war exposure.

Exposure to trauma after arrival in Norway was measured at T3 by asking 15 trauma exposure questions (i.e. sexual abuse, physical violence (at home or in the community), serious bullying, war/terror, natural disaster, death of a close person, serious accident, hospitalization or severe illness. Answer alternatives are yes/no. A total score of number of trauma experiences were calculated.

Daily hassles were measured by the Daily Stressors Scale for Young Refugees (DSSYR) (Vervliet, Lammertyn, Broekaert, \& Derluyn, 2014) at T3. This scale includes 16 questions on experiences of daily stress and negative life events (e.g. social stressors, material stressors, discrimination, and other stressors related to their specific situation such as feelings of insecurity, worries about family) the last month, on a scale from 1 (not at all) to 4 (very much). Responses were summed, so that a higher score indicates more daily stress. In the current study, the Cronbach's alpha was .88. 
Social support was measured by seven items from the Duke-UNC Functional Social Support Questionnaire, FSSQ [45] at T3. In the current study, item 5 about economic support was omitted. It is scored from 1 (much less than I would like to) to 5 (as much as I would like). A summed score was calculated. A higher score indicates higher levels of social support. In the current study, the Cronbach's alpha was .86.

\section{Analyses}

To address aim 1, linear mixed effect models were used. We regressed anxiety symptoms, depression symptoms, externalizing, and posttraumatic stress symptoms on time treated as a categorical predictor. To address aim 2, we conducted two sets of analyses. First, we conducted analyses regressing the four outcome variables on background predictors (age, gender, and trauma exposure prior to arrival). Second, we did a new set of analyses adding interaction terms between time and these predictors. In these models age was centered at 15 years, and number of prior trauma exposure was centered at 5 , and if interaction effects were significant or close to significant, we also investigated whether centering at other values (somewhat lower and higher than the original centering) would provide similar results. Aim 3 was addressed by descriptive analyses, and aim 4 by using linear regression models. Anxiety symptoms, depression symptoms, externalizing, posttraumatic stress symptoms, and somatization at T3 were regressed on the concurrent predictors (social support, daily hassles, and trauma exposure after T1). Linear regression models and mixed effects models were estimated using the R, with packages nlme [46], and lm.beta [47].

\section{Missing data}

Most of the missing data was due to wave nonresponse. Among the 98 participants, 46 $(46.9 \%)$ provided data at all three time points; $33(33.7 \%)$ provided data at two of three time points (either at T1 and T2, T2 and T3, or T1 and T3), whereas 19 (19.4\%) provided data at only one time point (T1, T2, or T3). To assess selective participation, the participation at T2 was regressed on scores of CPSS and HSCL at T1, and participation at T3 was regressed on scores of CPSS and HSCL at T1 and T2 (separately). Logistic regressions indicated that missing data were not significantly related to neither CPSS nor HSCL. For research question 1 and 2, the total sample $(n=98)$ was used. For research question 3 and 4 , the individuals who were reachable at five years follow-up $(n=47)$ was used. Total scores were computed if the participant had responded to at least half of the items of the scale (according to the "half item rule"). 


\section{Results}

\section{Change in mental health problems}

Table 1 presents descriptive characteristics of the main study variables in this study. At T1, our sample consisted of 95 individuals ( $80 \%$ boys, $\mathrm{n}=76$ ), and the mean age was 13.8 years. Prior to their arrival in Norway, the participants had experienced a mean of 5.7 stressful life events, the most prevalent being death of a close person $(66 \%, n=63)$, witnessing violence $(66 \%, \mathrm{n}=63)$, and $\operatorname{war}(66 \%, \mathrm{n}=62)$. The percentages scoring above cutoff on general psychological distress were 22.6 at T1, 20.0 at T2, and 19.6 at T3, whereas the percentages scoring above cutoff on posttraumatic stress symptoms at the same time points were $62.5,55.8$, and 41.9 . Box and whisker plots of anxiety symptoms, depression symptoms, externalizing, and posttraumatic stress at all three time points are presented in Figure 1. As can be seen, the respondents scored over time relatively high on symptoms of anxiety, depression, and posttraumatic stress, and relatively low on externalizing symptoms.

Table 2 shows that the unaccompanied refugee minors reported significantly lower levels of symptoms of depression, and marginally significant lower levels of posttraumatic stress after five years in Norway compared to at six months after arrival. No significant differences between $\mathrm{T} 1$ and $\mathrm{T} 2$ were found. In addition, no significant overall time differences in anxiety symptoms or externalizing were found. Thus, whereas we found no evidence indicating that the mean levels of mental health problems changed during the first two years, the mean levels of depression had decreased at five years after arrival.

\section{Predictors of change in mental health problems}

Adjusted for time, age and traumatic exposure, female gender was associated with higher levels of both symptoms of anxiety, depression, and posttraumatic stress symptoms, but not with externalizing symptoms (see Table 3). Similarly, adjusted for time, age, and gender, higher level of prior trauma exposure was associated with higher levels of anxiety, depression, and posttraumatic stress symptoms. Age was not significantly related to any of the mental health problems. Thus, prior trauma exposure and female gender, but not age, were associated with higher levels of mental health problems.

In order to test whether the effects of time on the four outcome variables were dependent upon levels of the predictors, we specified a model that included interaction between time and each of the predictors. For anxiety symptoms, we found no significant interaction effects between time and gender $(\mathrm{p}=.111)$ or time and prior exposure $(\mathrm{p}=.170)$, but a significant interaction between time and age $(\mathrm{p}=.034)$. Inspection the plot of the course 
of estimated anxiety symptoms over time (Figure 2, left panel) reveals that young age is associated with a more positive course over time. This suggest that lower age was associated with a greater effect of time on anxiety symptoms; that older adolescents reported a slower rate of recovery compared to the younger adolescents.

For depressive symptoms, we found no significant interaction effects between time and age $(\mathrm{p}=.114)$, time and prior exposure $(\mathrm{p}=.568)$, and a marginally significant interaction between time and gender $(\mathrm{p}=.047)$. However, instable results shown by wide confidence intervals for random effects weaken our confidence in this model. Furthermore, for externalizing, we found no significant interaction between time and gender $(p=.500)$, time and prior exposure $(\mathrm{p}=.732)$, or time and age $(\mathrm{p}=.095)$.

There were no significant interactions between time and gender $(p=.507)$, or time and prior exposure $(\mathrm{p}=.172)$, on posttraumatic stress symptoms. In contrast, we found a significant interaction effect between time and age $(\mathrm{p}=.001)$. Similar as for anxiety symptoms, the interaction plot (Figure 2, right panel) indicates that young age is associated with a more positive course over time.

\section{Mental health status five years after arrival, and predictors}

Even though the average levels of symptoms of depression and posttraumatic stress had decreased five years after arrival, a considerable percentage of these youth still reported mental health problems. As can be seen in Table 1, approximately $24 \%$ scored over cut off for depression symptoms, $15 \%$ over cutoff for anxiety symptoms, and $42 \%$ scored above cutoff for posttraumatic stress symptoms. Furthermore, the mean level of somatization (range $0-32)$ was $14.0(\mathrm{SD}=7.6)$.

Next, we examined predictors of mental health status five years after arrival. Approximately $60 \%$ reported that they receive less social support than they would like on at least one of the seven items. For example, $32 \%$ reported that they experience "much less than they would like", "less than they would like", or "some, but would like more" of the following: "I have people around me who cares about what happens to me." The most common daily hassles that the youth responded "much" or "very much" to were: too little money $(27 \%)$, feeling unsafe $(22 \%)$, unsure about the future $(20 \%)$, and difficulties getting documents from the authorities (17\%). Furthermore, the youth reported a mean number of 2.7 new traumas after arrival to Norway. More specifically, $55 \%$ of those who responded $(\mathrm{n}=$ 24) had witnessed violence, $51 \%(n=23)$ had experienced the death or illness by close person, $33 \%(\mathrm{n}=15)$ had witnessed violence where they live, $24 \%(\mathrm{n}=11)$ had experienced 
a medical trauma, $27 \%(\mathrm{n}=12)$ reported a serious accident, $21 \%(\mathrm{n}=9)$ a natural disaster, $16 \%(n=7)$ having been beaten or hurt by another person, $13 \%(n=6)$ had experienced bullying, $9 \%(\mathrm{n}=4)$ had experienced having been beaten, hit or threatened to be beaten or hit by an employee where they have lived, and $4 \%(n=2)$ had been sexual assaulted.

Table 4 presents relationships between these predictors (social support, daily hassles, and trauma exposure after arrival) and concurrent mental health problems (symptoms of anxiety, depression, externalizing, posttraumatic stress, and somatization) five years after arrival. Unadjusted, low levels of social support and high levels of daily hassles was associated with high levels of symptoms of anxiety, depression, externalizing, as well as posttraumatic stress symptoms. Trauma exposure after arrival was not significantly associated with any of the mental health problems. Only high levels of daily hassles but not social support or trauma exposure after arrival was significantly associated with high levels of somatization. When adjusted for each other, the associations between high levels daily hassles and high levels mental health problems were the only that remained significant.

\section{Discussion}

This study aimed to increase our knowledge about the mental health status of the youngest unaccompanied refugee minors after five years in Norway, and to identify predictors of changes in their mental health during these five years. There were four main findings.

First, whereas there was little change from arrival to two years after, the mean levels of depression had decreased at five years. In contrast, neither levels of externalizing symptoms, anxiety, nor posttraumatic stress symptoms seemed to have changed substantially. Second, female gender and high levels of trauma exposure were associated with general high levels of all symptoms, except externalizing, over the five years. In addition, higher age was associated with less change in symptoms of depression and posttraumatic stress over time. Third, five years after arrival a considerable percentage still experienced clinical levels of mental health problems. For example, $15 \%$ reported depressive symptoms above the clinical cut-off, $24 \%$ reported anxiety symptoms above the clinical cut-off, and $42 \%$ reported clinically significant levels of posttraumatic stress symptoms. In addition, many reported health problems such as head- and stomachaches. Lastly, high levels of mental health problems five years after arrival was associated with both low levels of social support and high levels of daily stress when not adjusted for each other. When both were taken into account, only levels of daily stress were associated with mental health problems. 
The finding that the level of mental health problems remain generally high after 5 years in Norway is disturbing. Particularly post-traumatic stress in children tends to become chronic if untreated [48], pointing to the need for better services for these youth. The finding that more trauma exposure is related to more mental health problems is not surprising and is in line with numerous studies [19]. Also, girls have been shown to be more at risk for developing post-traumatic stress reactions than boys, possibly a reflection of more interpersonal trauma experiences [19]. The older children were also particularly at risk. This is in line with meta analyses showing that older age is associated with more stable trajectories (i.e. less reduction in symptoms), at least for PTSD [48]. In this study we expected younger age to be a risk factor since these youth had fled from their home countries without adult protection and comfort and thus had little help from trusting adults to make meaning of their experiences and help regulate affect. This unexpected finding may, however, reflect that the younger children were more often placed in foster homes and therefore had more opportunities for building trusting relationships and to establish new adult attachment figures.

Studies have shown that experiencing multiple childhood adverse experiences lead to a range of mental health problems and that childhood adversities are associated with almost $30 \%$ of all onsets of psychiatric disorders [49]. The findings in this study shows that the youth not only have experienced multiple traumas in their home countries and during flight, but that many continue to experience new traumas and have many daily hassles to overcome in their host country. The finding that many had experienced new traumas and particularly violence in their homes after arrival, (although this was not found to predict the sustainment of mental health problems), is alarming. Although the youth cannot be protected from all adversities, such as the death of family members in their home countries, which was commonly reported, they should be able to feel safe in their own homes. Taking into consideration the cumulative risk related to adversities, effort should be put into reduce exposure to new adversities.

High levels of daily hassles was also associated with all mental health problems and somatic complaints. This finding is in line with other studies showing that the number of daily hassles lead to higher symptom levels of depression [13,36], anxiety and PTSD [13], albeit no studies have examined the relationship between somatic complaints and daily hassles before. Daily hassles are day-to-day routine challenges that all youth experience [50], and although they may be relatively minor or routine, studies have shown they tend to have more proximal effects on well-being than many major life events [51]. According to Almeida [52], daily hassles exert their influence through separate and immediate direct effects on emotional and 
physical functioning. They tend to accumulate and create continual frustration that increase the risk of serious mental health problems. In this study the youth's earlier experiences seem to be exacerbated by post-migration stress, such as uncertainty about asylum status, loneliness, and worry. These youth also have to learn a new language and understand the cultural environment in school and in the workplace. The results suggest therefore that support is needed not only to handle pre-migration traumatization, but also to address ongoing and everyday stress and hassles experienced during resettlement.

The youth in this study are in a period of transition from childhood to adulthood, a period many experiences as challenging. While most adolescents have family to support them in this transition, most unaccompanied refugee minors do not, and this study underscores the importance social support may have on adjustment. Social support has been found to alleviate effects of both trauma [29,18,30], and daily stress [53]. For example, La Greca, Silverman, Lai, and Jaccard [54] identified less social support, high anxiety and poor emotion regulation as key predictors of whether elevated PTSD symptoms would decline or remain chronic. Oppedal and Idsoe [24] found that social support had direct effects on depression but not PTSD in a group of resettled unaccompanied minors. They also found that social support had indirect effects though increasing culture competence that may aid the young refugees in dealing with discrimination which again is a source of daily stress. A study by Sierau and colleagues from Germany [30] showed that support from different social networks may have different effects on youth's mental health trajectories. In the current study, high levels of mental health problems was associated with both low levels of social support and high levels of daily hassles but when both were taken into account, only levels of daily hassles were associated with mental health problems. Taken together the findings suggest that helping youth build social relationships that are supportive, seeking to alleviate daily hassles that cause stress in their lives, reducing the risk for new traumatization and providing help for prevailing mental health issues and somatic complaints should be the target for social and psychological interventions.

This study adds to our understanding about an understudied group, and has several strengths. First, not many studies have focused on the youngest group of unaccompanied refugee minors, and to our knowledge, none have examined mental health changes over a period of five years for this young group of children. It is also considered a strength that the study included females as this is a group that is underrepresented in most studies on unaccompanied refugee minors. Secondly, hardly any studies have examined somatic complaints in refugee children. Third, the relationship between risk (early and ongoing 
trauma, daily hassles) and protective factors (social support) is poorly understood and this study contributes to our knowledge of important factors that may contribute to the development and maintenance of mental health problems in this highly vulnerable group of children. However, the results must be understood in light of some study limitations. One major limitation is that only approximately half of the participants that participated at T1 participated at T3. However, a high rate of dropout was to be expected due to the long period of follow-up and the fact that refugees can be difficult to find and often leave the host country for various reasons. Missing data were not significantly related to previous levels of CPSS or HSCL, yet it cannot be ruled out that we had too low power to detect such effects. Another limitation is that there are considerable variability in time interval between measurements. This means that the effects of categorical variable of time (T2, T3) on the outcomes needs to be interpreted with caution. In addition, the study sample included a low number of girls. However, three out of four unaccompanied refugee minors in Norway are boys, and the gender distribution in the current study reflects this.

\section{Implications}

This study is the first to examine long term predictors of metal health trajectories for unaccompanied refugee youth under the age of 17. The findings highlight how vulnerable these youth are. They not only experience multiple traumas before and during flight but also after resettlement. Although most felt safe in Norway, an alarmingly high percentage reported serious violence episodes, both in their homes and in the community. This was somewhat surprising since Norway has relatively little community violence compared to many other countries. Qualitative interviews show that many of these have experience interpersonal violence in their primary families and in school in their home countries [8]. In light of an overwhelming amount of literature consistently documenting the relationship between multitraumatization and a range of mental and physical health problems measures need to be taken to protect these youths against further traumatization. In addition, the study documents the many daily hassles the youth experience and this seems to exacerbate their situation. More longitudinal studies are needed to be able to understand the relationship between early and ongoing stressors. It is possible that early traumatic experiences have a larger impact in the earlier phases of life in exile while daily stress and hassles are more important in the long term. Either way understanding the impact of everyday obstacles these youth face is important for clinicians and authorities. The finding that experienced social support is associated with fewer problems is encouraging. Building social networks around these youth seems 
worthwhile and may lead to better integration. The youngest of the children are often put in foster homes and these seem to be more resilient. Since support from adults seems to mitigate the effects of negative life experiences [30], building robust and stable networks with trusting adults is important. Youth who have suffered many losses and experienced continuous betrayal from adults may, however, not be able to accept support and affection from others. Providing therapy to these youth may be necessary not only to alleviate mental health problems and reduce the effects of trauma, but also to restore trust in other people. Having trusting relationships to others serves several functions, and for unaccompanied refugee youths who, in addition to facing normal developmental challenges transitioning from childhood to adolescents, have to face challenges related to acculturation and migration, this cannot be underestimated.

\section{Ethical standards}

The study has been approved by The National Committee for Medical and Health Research Ethics and has therefore been performed in accordance with the ethical standards laid down in the 1964 Declaration of Helsinki and its later amendments. All persons gave their informed consent prior to their inclusion in the study. Details that might disclose the identity of the subjects under study has been omitted.

\section{Conflict of interest}

The authors declare that they have no conflict of interest.

\section{References}

1. UNHCR (2016) Global trends in forced displacement in 2016. UNHCR, Geneva, Switzerland

2. Derluyn I, Lippens V, Verachtert T, Bruggeman W, Broekaert E (2010) Minors Travelling Alone: A Risk Group for Human Trafficking? International Migration 48 (4):164-185. doi:10.1111/j.14682435.2009.00548.x

3. Bean T, Derluyn I, Eurelings-Bontekoe E, Broekaert E, Spinhoven P (2007) Comparing psychological distress, traumatic stress reactions, and experiences of unaccompanied refugee minors with experiences of adolescents accompanied by parents. Journal of Nervous and Mental Disease 195 (4):288-297. doi:10.1097/01.nmd.0000243751.49499.93

4. Hebebrand J, Anagnostopoulos D, Eliez S, Linse H, Pejovic-Milovancevic M, Klasen HJEC, Psychiatry A (2016) A first assessment of the needs of young refugees arriving in Europe: what mental health professionals need to know. 25 (1):1-6. doi:10.1007/s00787-015-0807-0 
5. Ramel B, Täljemark J, Lindgren A, Johansson BAJS (2015) Overrepresentation of unaccompanied refugee minors in inpatient psychiatric care. 4 (1):131. doi:10.1186/s40064-015-0902-1

6. Vervliet M, Meyer Demott MA, Jakobsen M, Broekaert E, Heir T, Derluyn I (2014) The mental health of unaccompanied refugee minors on arrival in the host country. Scand J Psychol 55 (1):33-37. doi:10.1111/sjop.12094

7. Jensen TK, Fjermestad KW, Granly L, Wilhelmsen NH (2015) Stressful life experiences and mental health problems among unaccompanied asylum-seeking children. Clinical Child Psychology and Psychiatry 20 (1):106-116. doi:10.1177/1359104513499356

8. Skårdalsmo EMB, Jensen TK (2015) Unaccompanied refugee minors' early life narratives of physical abuse from caregivers and teachers in their home countries. Child Abuse \& Neglect 48:148-159. doi:http://dx.doi.org/10.1016/j.chiabu.2015.08.003

9. Jakobsen M, Demott MAM, Heir T (2014) Prevalence of psychiatric disorders among unaccompanied asylum-seeking adolescents in norway. Clinical practice and epidemiology in mental health : CP \& EMH 10 (1):53. doi:10.2174/1745017901410010053

10. Hodes M, Vasquez MM, Anagnostopoulos D, Triantafyllou K, Abdelhady D, Weiss K, Koposov R, Cuhadaroglu F, Hebebrand J, Skokauskas NJEC, Psychiatry A (2018) Refugees in Europe: national overviews from key countries with a special focus on child and adolescent mental health. 27 (4):389399. doi:10.1007/s00787-017-1094-8

11. Jensen TK, Skårdalsmo EMB, Fjermestad KW (2014) Development of mental health problems - a follow-up study of unaccompanied refugee minors. Child and Adolescent Psychiatry and Mental Health 8:29. doi:10.1186/1753-2000-8-29

12. Keles S, Friborg O, Idsøe T, Sirin S, Oppedal B (2018) Resilience and acculturation among unaccompanied refugee minors. International Journal of Behavioral Development 42 (1):52-63. doi:10.1177/0165025416658136

13. Vervliet M, Lammertyn J, Broekaert E, Derluyn IJEC, Psychiatry A (2014) Longitudinal follow-up of the mental health of unaccompanied refugee minors. 23 (5):337-346. doi:10.1007/s00787-013-04631

14. Derluyn I, Mels C, Broekaert E (2009) Mental Health Problems in Separated Refugee Adolescents. Journal of Adolescent Health 44 (3):291-297. doi:http://dx.doi.org/10.1016/i.jadohealth.2008.07.016 15. Hodes M, Jagdev D, Chandra N, Cunniff A (2008) Risk and resilience for psychological distress amongst unaccompanied asylum seeking adolescents. Journal of Child Psychology and Psychiatry 49 (7):723-732. doi:10.1111/j.1469-7610.2008.01912.x

16. Almqvist K, Broberg AG (1999) Mental Health and Social Adjustment in Young Refugee Children y 31/2 Years After Their Arrival in Sweden. Journal of the American Academy of Child \& Adolescent Psychiatry 38 (6):723-730. doi:http://dx.doi.org/10.1097/00004583-199906000-00020 
17. Reavell J, Fazil Q (2017) The epidemiology of PTSD and depression in refugee minors who have resettled in developed countries. Journal of Mental Health 26 (1):74-83.

doi:10.1080/09638237.2016.1222065

18. Fazel M, Reed RV, Panter-Brick C, Stein A (2012) Mental health of displaced and refugee children resettled in high-income countries: risk and protective factors. The Lancet 379 (9812):266-282. doi:https://doi.org/10.1016/S0140-6736(11)60051-2

19. Trickey D, Siddaway AP, Meiser-Stedman R, Serpell L, Field AP (2012) A meta-analysis of risk factors for post-traumatic stress disorder in children and adolescents. Clin Psychol Rev 32. doi:10.1016/j.cpr.2011.12.001

20. Spiller TR, Schick M, Schnyder U, Bryant RA, Nickerson A, Morina N (2016) Somatisation and anger are associated with symptom severity of posttraumatic stress disorder in severely traumatised refugees and asylum seekers. Swiss Medical Weekly 146 (14311).

doi:https://doi.org/10.4414/smw.2016.14311

21. Teodorescu D-S, Heir T, Siqveland J, Hauff E, Wentzel-Larsen T, Lien L (2015) Chronic pain in multi-traumatized outpatients with a refugee background resettled in Norway: a cross-sectional study. BMC Psychology 3 (7). doi:10.1186/s40359-015-0064-5

22. Kien C, Sommer I, Faustmann A, Gibson L, Schneider M, Krczal E, Jank R, Klerings I, Szelag M, Kerschner B, Brattström P, Gartlehner GJEC, Psychiatry A (2018) Prevalence of mental disorders in young refugees and asylum seekers in European Countries: a systematic review. doi:10.1007/s00787018-1215-z

23. Geltman PL, Grant-Knight W, Ellis H, Landgraf JM (2008) The "lost boys" of Sudan: Use of health services and functional health outcomes of unaccompanied refugee minors resettled in the U.S. J Immigrant Minority Health 10 (5):389-396

24. Oppedal B, Idsoe T (2015) The role of social support in the acculturation and mental health of unaccompanied minor asylum seekers. . Scand J Psychol 56 (2):203-211. doi:10.1111/sjop.12194 25. Tozer M, Khawaja NG, Schweitzer R (2018) Protective Factors Contributing to Wellbeing Among Refugee Youth in Australia. Journal of Psychologists and Counsellors in Schools 28 (1):66-83. doi:10.1017/jgc.2016.31

26. Montgomery E (2010) Trauma and resilience in young refugees: A 9-year follow-up study. Development and Psychopathology 22 (02):477-489. doi:doi:10.1017/\$0954579410000180 27. Thoresen S, Jensen TK, Wentzel-Larsen T, Dyb G (2014) Social support barriers and mental health in terrorist attack survivors. Journal of Affective Disorders 156 (0):187-193.

doi:http://dx.doi.org/10.1016/j.jad.2013.12.014

28. Thoits PA (2011) Mechanisms linking social ties and support to physical and mental health.0022146510395592. J Health Soc Behav 52 (2):145.-161. doi:10.1177/ 
29. Brewin CR, Andrews B, Valentine JD (2000) Meta-analysis of risk factors for posttraumatic stress disorder in trauma-exposed adults. Journal of Consulting and Clinical Psychology 68 (5):748-766 30. Sierau S, Schneider E, Nesterko Y, Glaesmer H (2018) Alone, but protected? Effects of social support on mental health of unaccompanied refugee minors. European child \& adolescent psychiatry. doi:10.1007/s00787-018-1246-5

31. Berthold SM (2000) War Traumas and Community Violence. Journal of Multicultural Social Work 8 (1-2):15-46. doi:10.1300/J285v08n01_02

32. Colic-Peisker V (2009) Visibility, settlement success and life satisfaction in three refugee communities in Australia. 9 (2):175-199. doi:10.1177/1468796809103459

33. Lustig SL, Kia-Keating M, Knight WG, Geltman P, Ellis H, Kinzie JD, Keane T, Saxe GN (2004) Review of child and adolescent refugee mental health Journal of American Academy of Child and Adolescent Psychiatry 43 (1):24-36. doi:10.1097/00004583-200401000-00012

34. Montgomery E (2011) Trauma, exile and mental health in young refugees. Acta Psychiatrica Scandinavica 124:1-46. doi:10.1111/j.1600-0447.2011.01740.x

35. Seglem KB, Oppedal B, Roysamb E (2014) Daily hassles and coping dispositions as predictors of psychological adjustment. International Journal of Behavioral Development 38 (3):293-303. doi:10.1177/0165025414520807

36. Keles S, Friborg O, Idsøe T, Sirin S, Oppedal B (2018) Resilience and acculturation among unaccompanied refugee minors. 42 (1):52-63. doi:10.1177/0165025416658136

37. Nickerson A, Liddell B, Asnaani A, Carlsson J, Fazel M, Knaevelsrud C, Morina N, Neuner F, Newnham E, Rasmussen A (2018) Trauma and Mental Health in Forcibly Displaced Populations: An International Society for Traumatic Stress Studies Briefing Paper. ISTSS

38. Bean TM, Eurelings-Bontekoe E, Derluyn I, Spinhoven P (2004) Hopkins Symptom Checklist-37A for Adolescents (HSCL-37A) User's Manual. .

39. Bean T, Derluyn I, Eurelings-Bontekoe E, Broekaert E, Spinhoven P (2007) Validation of the multiple language versions of the Hopkins symptom checklist - 37 for refugee adolescents. . Adolescence 42 (165):51-71

40. Bronstein I, Montgomery P, Ott E (2013) Emotional and behavioural problems amongst Afghan unaccompanied asylum-seeking children: results from a large-scale cross-sectional study. European child and adolescent psychiatry 22:285-294. doi:10.1007/s00787-012-0344-z

41. Foa EB, Johnson KM, Feeny NC, Treadwell KR (2001) The Child PTSD Symptom Scale:a preliminary examination of its psychometric properties. J Clin Child Psychol 30.

doi:10.1207/s15374424jccp3003_9 
42. Walker LS, Beck JE, Garber J, Lambert W (2009) Children's Somatization Inventory: Psychometric Properties of the Revised Form (CSI-24). Journal of Pediatric Psychology 34 (4):430-440.

doi:10.1093/jpepsy/jsn093

43. Stene LE, Dyb G (2015) Health service utilization after terrorism: A longitudinal study of survivors of the 2011 Utøya attack in Norway. . BMC Health Services Research 15 (1). doi:10.1186/s12913-0150811-6

44. Bean TM, Eurelings-Bontekoe E, Derluyn I, Spinhoven P (2004) Stressful life events (SLE): User's Manual. Centrum '45, Oegstgeest.

45. Broadhead WE, Gehlbach SH, DeGruy FV, Kaplan BH (1988) TheDuke-UNC Functional Social Support Questionnaire. Measurement of social support in family medicine patients. . Med Care 26 (7):709-723. doi:10.1097/00005650-198807000-00006

46. Pinheiro J, Bates D (2000) Mixed Effects Models in S and S-Plus. Springer-Verlag, New York. doi:10.1007/978-1-4419-0318-1

47. Behrendt S (2014) Im.beta. R-package v1.5-1. https://cran.r-project.org/package=Im.beta. 48. Hiller RM, Meiser-Stedman R, Fearon P, Lobo S, McKinnon A, Fraser A, Halligan SL (2016) Research Review: Changes in the prevalence and symptom severity of child post-traumatic stress disorder in the year following trauma - a meta-analytic study. Journal of Child Psychology and Psychiatry 57 (8):884-898. doi:doi:10.1111/jcpp.12566

49. McLaughlin KA, Greif Green J, Gruber MJ, Sampson NA, Zaslavsky AM, Kessler RC (2012) Childhood adversities and first onset of psychiatric disorders in a national sample of us adolescents. Archives of General Psychiatry 69 (11):1151-1160. doi:10.1001/archgenpsychiatry.2011.2277 50. Burkhart ML, Horn Mallers M, Bono KE (2017) Daily Reports of Stress, Mood, and Physical Health in Middle Childhood. Journal of Child and Family Studies 26 (5):1345-1355. doi:10.1007/s10826-0170665-0

51. Almeida DM (2005) Resilience and Vulnerability to Daily Stressors Assessed via Diary Methods. 14 (2):64-68. doi:10.1111/j.0963-7214.2005.00336.x

52. Almeida DM, Piazza JR, Stawski RS, Klein LC (2011) Chapter 12 - The Speedometer of Life: Stress, Health and Aging. In: Schaie KW, Willis SL (eds) Handbook of the Psychology of Aging (Seventh Edition). Academic Press, San Diego, pp 191-206. doi:https://doi.org/10.1016/B978-0-12-380882-

\section{$\underline{0.00012-7}$}

53. Sirin SR, Gupta T, Ryce P, Katsiaficas D, Suárez-Orozco C, Rogers-Sirin L (2013) Understanding the role of social support in trajectories of mental health symptoms for immigrant adolescents. Journal of Applied Developmental Psychology 34 (5):199-207.

doi:https://doi.org/10.1016/j.appdev.2013.04.004 
54. La Greca AM, Silverman WK, Lai B, Jaccard J (2010) Hurricane-related exposure experiences and stressors, other life events, and social support: Concurrent and prospective impact on children's persistent posttraumatic stress symptoms. Journal of Consulting and Clinical Psychology 78 (6):794805. doi:10.1037/a0020775 